\title{
Static pressure-volume curves and body posture in severe chronic bronchitis
}

\author{
S.D. Mentzelopoulos, J. Sigala, C. Roussos and S.G. Zakynthinos
}

ABSTRACT: Based on prior data, the current authors hypothesised that beneficial pronation effects on gas exchange and respiratory mechanics might be maximised in severely hyperinflated chronic bronchitis patients. The current authors also sought to elucidate underlying mechanisms and to determine whether pronation effects are reflected by postural changes in inspiratory pressure-volume (P-V) curve characteristics.

A total of 16 mechanically ventilated patients (for 16-36 h) with chronic bronchitis exacerbation were studied in pre-prone semirecumbent (SREC), prone and post-prone SREC postures. Static respiratory system intrinsic positive end-expiratory pressure ( $\mathrm{PEEPi}, \mathrm{rs})$ was $>12 \mathrm{cmH}_{2} \mathrm{O}$. Haemodynamics, partitioned respiratory mechanics, gas exchange, and lung volumes were determined at zero external positive end-expiratory pressure. P-V curves were constructed from functional residual capacity.

End-expiratory lung volume exceeded opening volume. Prone position versus pre-prone SREC resulted in $20 \%$ reduced pressure at the lower inflection point (LIP) and $17 \%$ increased volume at the upper inflection point of the lung P-V curve, improved lung mechanics and volumes, oxygenation, and carbon dioxide arterial tension $\left(\mathrm{Pa}_{\mathrm{a}} \mathrm{CO}_{2}\right)$. In multiple linear regression, postural decreases in $\mathrm{PEEP}$,rs and additional lung resistance independently predicted postural decreases in lung LIP pressure and $\mathrm{Pa}_{1} \mathrm{CO}_{2}$, respectively.

In conclusion, in severely hyperinflated patients, pronation reduces lung lower inflection point pressure and increases lung upper inflection point volume. Pronation effects on ventilation homogeneity and carbon dioxide arterial tension are maximised, implying that pronation can be useful during early controlled ventilation.

KEYWORDS: Chronic bronchitis, chronic obstructive pulmonary disease, pressure-volume curves, prone position, recruitment, respiratory mechanics

$\mathrm{n}$ chronic obstructive pulmonary disease (COPD), prone position versus semirecumbent increases lung compliance, reduces airway and additional lung resistance, attenuates dynamic hyperinflation and improves oxygenation [1-3]. Carbon dioxide arterial tension $\left(\mathrm{Pa}, \mathrm{CO}_{2}\right)$ does not decrease significantly [1-3]. Pronation effects on expiratory resistance and hyperinflation were explained by a potentially more homogenous distribution of alveolar septal tension exerted on airway walls [2]. These findings were obtained from chronic bronchitis patients with mainly moderate hyperinflation; mean static respiratory system intrinsic positive endexpiratory pressure (PEEPi,rs) was $\sim 9 \mathrm{cmH}_{2} \mathrm{O}$. Based on prior data [4], the current authors defined severe hyperinflation as $\mathrm{PEEPi}, \mathrm{rs}>12 \mathrm{cmH}_{2} \mathrm{O}$. Such levels of PEEPi,rs have been measured during early (duration $<36 \mathrm{~h}$ ) controlled ventilation [4]. In two prior studies $[1,2]$, there were three patients with $\mathrm{PEEPi}$,rs $>12 \mathrm{cmH}_{2} \mathrm{O}$ determined during early controlled ventilation. In these patients, prone position versus semirecumbent had resulted in the maximal observed $\mathrm{Pa}, \mathrm{CO}_{2}$ drop of $18.1-22.0 \%$ and a concurrent drop of $42.3-48.4 \%$ in additional lung resistance. In COPD, gas exchange disturbances may be partially explained by enhanced ventilation heterogeneity [5-7]. Alternatively, prone position probably causes a more uniform distribution of ventilation $[1,2]$. Thus, the current authors hypothesised that in severely hyperinflated COPD patients, pronation effects may be maximised and this could be primarily reflected in an increase in effective alveolar ventilation causing a significant decrease in $\mathrm{Pa}, \mathrm{CO}_{2}$.

The current authors also sought to further elucidate the mechanisms underlying pronation effects [2]. Therefore, in addition to respiratory mechanics, lung volumes and gas exchange [1, 2] the present authors studied the effects of body posture on inspiratory pressure-volume $(\mathrm{P}-\mathrm{V})$ curves, as it was anticipated that pronation

\section{AFFILIATIONS}

University of Athens Medical School Evaggelismos Hospital, Athens, Greece.

CORRESPONDENCE

S.G. Zakynthinos

Dept of Intensive Care Medicine University of Athens Medical School Evaggelismos Hospital 45-47 Ipsilandou Str GR 10675

Athens

Greece

Fax: 302107216503

E-mail: szakynthinos@yahoo.com

Received:

January 212006

Accepted after revision:

March 222006

\section{SUPPORT STATEMENT}

The present study was funded solely by the Dept of Intensive Care Medicine, Evaggelismos General Hospital, Athens, Greece. 
effects would be reflected by changes in P-V curve characteristics. These characteristics include a lower inflection point (LIP) and an upper inflection point (UIP). The LIP indicates the threshold opening pressure of previously collapsed small airways [8]. Thus, improvements in ventilation homogeneity could be accompanied by a reduction in LIP pressure of the lung $\mathrm{P}-\mathrm{V}$ curve. The UIP reflects alveolar and lung tissue overdistension at high inflation volumes. Thus, a potential reduction in functional residual capacity (FRC) and enhanced ventilation homogeneity resulting in reduced number of overdistended/hyperinflated alveoli [1,2] could be accompanied by an increase in UIP inflation volume of the lung P-V curve. Finally, the current authors sought to determine the opening volume and its relationship with end-expiratory lung volume (EELV) [8]. The opening volume reflects the lung volume at which small airways reopen during inflation from FRC [8]. In COPD, the EELV/opening volume relationship may provide information regarding cyclic small airway closure/reopening, which can predispose to low-volume barotrauma [8].

\section{MATERIAL AND METHODS \\ Patients}

The Evaggelismos Hospital Scientific Committee (Athens, Greece) gave approval to the study and informed, written consent from the next of kin was obtained. Initially, 16 consecutive, severe chronic bronchitis patients [9-11] were considered for enrolment. Five patients were excluded due to PEEPi,rs $<12 \mathrm{cmH}_{2} \mathrm{O}$. Within 3-6 months another five consecutive patients were studied. Consequently, 16 nonconsecutive patients were ultimately studied. Patients were orotracheally intubated (No. 8.0-8.5, endotracheal tube 26 $\mathrm{cm}$; Portex, Kent, UK) and mechanically ventilated (Siemens 300C; Siemens, Berlin, Germany) in the semirecumbent (SREC) position $\left(45^{\circ}\right.$ inclination). Patients were poor responders to bronchodilators $[10,11]$ during the pre-admission period of clinical stability and were intubated for acute bronchitisinduced respiratory failure $[1,2]$.

Patients were enrolled after $16-36 \mathrm{~h}$ of controlled ventilation. Under anaesthesia, PEEPi,rs was $>12 \mathrm{cmH}_{2} \mathrm{O}$. External positive end-expiratory pressure (PEEP) was $0 \mathrm{cmH}_{2} \mathrm{O}$ during the 6-h study period. Table 1 displays patient characteristics and baseline ventilator settings employed throughout the study period. Plateau airway pressure ranged within $20-30 \mathrm{cmH}_{2} \mathrm{O}$.

Exclusion criteria included: 1) left ventricular failure; 2) myocardial ischaemia; 3) lobar atelectasis; 4) pneumonia; 5) sepsis; and 6) pulmonary embolism. During the study period, patient care was provided by an independent physician. Any new/additional administration of fluid boluses, inotropes, antipyretics, vasodilators, antiarrhythmics, diuretics, or insulin would cause patient exclusion [1, 2]. Bronchodilator drugs were withheld for $6 \mathrm{~h}$ before and throughout the study period. Throughout the study, electrocardiographic lead II, intraarterial/pulmonary artery pressures, cardiac output and mixed-venous oxygen saturation (744F75 CCOmbo SwanGanz catheter; Edwards Lifesciences, Irvine, CA, USA), bladder temperature (Mon-a-therm $\mathrm{IM}$, Foley-Temp $\mathrm{IM}$; Malinckrodt, St Louis, MO, USA), and peripheral oxygen saturation were continuously monitored. Any enteral nutrition was replaced by isocaloric parenteral nutrition, gastric contents were evacuated by suction and the nasogastric tube was

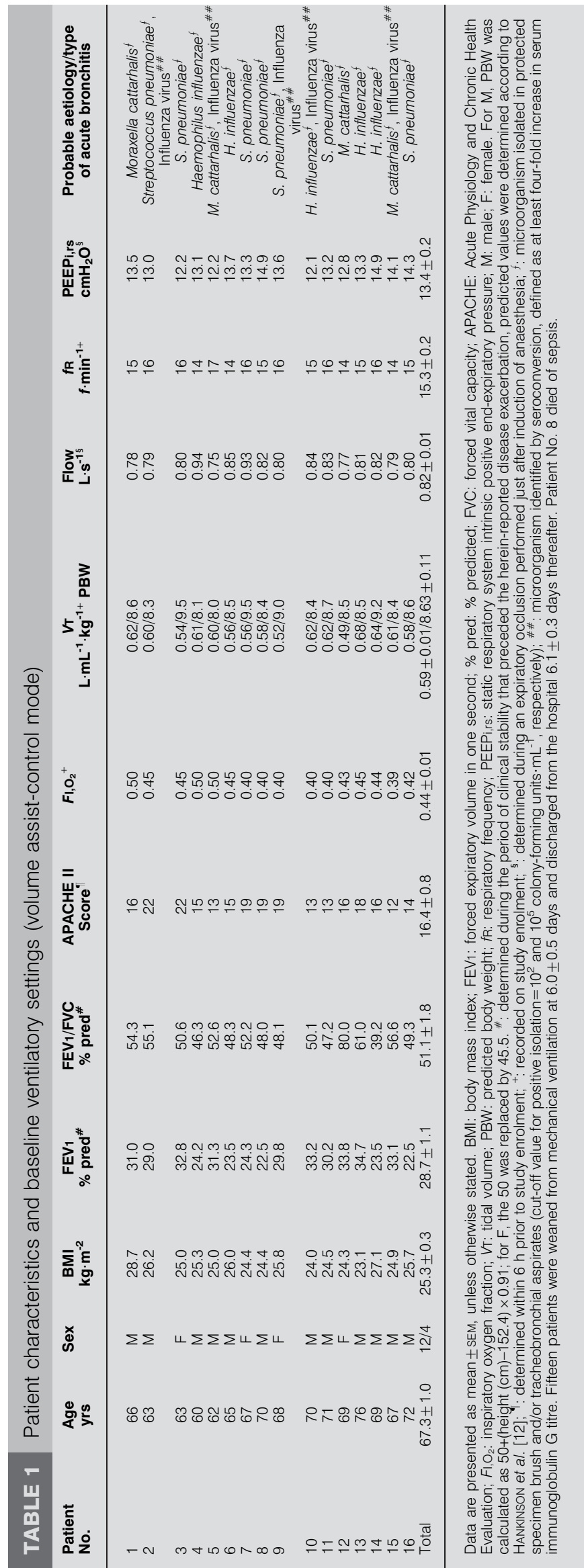


removed [1]. Oesophageal and gastric balloons were inserted and their correct positioning was verified as previously described [1, 2, 13, 14]. Following colloid infusion (3$\left.5 \mathrm{~mL} \cdot \mathrm{kg}^{-1}\right)$, anaesthesia was induced and maintained throughout the study period with propofol/fentanyl to achieve respiratory muscles inactivity [2].

\section{Protocol and measurements}

Flow, tracheal, oesophageal and gastric pressures were measured using a heated pneumotachograph (Hans-Rudolph, Kansas City, MT, USA) and pressure transducers (Validyne, Nortridge, CA, USA) [1, 2]. Volume was obtained by flow signal integration over time. Data were analysed with Anadat software. Transpulmonary pressure was calculated as trachealto-oesophageal pressure difference. Breathing circuit modifications comprised removal of humidifier and use of low compliance tubing [15]. Equipment dead space (endotracheal tube not included) was $90 \mathrm{~mL}$.

$\mathrm{P}-\mathrm{V}$ curves were constructed and haemodynamics, gas exchange, respiratory mechanics and lung volumes were assessed in baseline (pre-prone) SREC ( $45^{\circ}$ inclination), prone and post-prone SREC $\left(45^{\circ}\right.$ inclination) positions. Patient turning and minimisation of abdominal movement restriction following pronation were achieved as previously described [1, 2]. The reliability of oesophageal pressure measurements was confirmed as previously reported [1, 2].

\section{Haemodynamics and gas exchange}

Haemodynamic measurements included heart rate; arterial, central venous and pulmonary artery pressures; cardiac output and mixed venous oxygen saturation. Variable values were recorded and averaged over 6-min periods. These periods corresponded to 30-35 min following assumption of each study-posture. Arterial and mixed venous blood gas analysis (ABL System 625; Radiometer, Copenhagen, Denmark) was performed at the beginning and end of the aforementioned period and the mean blood gas values were analysed for each posture. Formula-derived variables are listed in Appendix I.

\section{Quasistatic inflation P-V curves}

In each posture, inflation $\mathrm{P}-\mathrm{V}$ curves of the respiratory system, chest wall and lung were constructed using a 2-L calibration syringe filled with $100 \%$ oxygen [16]. At 35-40 min after studyposture assumption, FRC was reached during a brief (20-55 s) disconnection from the ventilator. The FRC level was confirmed by expiratory occlusion(s) resulting in an end-expiratory pressure of $0 \mathrm{cmH}_{2} \mathrm{O}$. The syringe was then connected to the endotracheal tube and inflation $\mathrm{P}-\mathrm{V}$ curves were obtained by sequentially adding volumes of $50 \mathrm{~mL}$ in steps of 2-3 s until the lungs were inflated with $200 \mathrm{~mL}$. Immediately after this, volumes of $100 \mathrm{~mL}$ were sequentially added in steps of 2-3 s until an inflation volume of $1,200 \mathrm{~mL}$ (first 11 patients) or $1,500 \mathrm{~mL}$ (last five patients) was reached. The P-V curves were always constructed within $40-60 \mathrm{~s}$. The lowest peripheral oxygen saturation allowed was $88 \%$.

\section{P-V curve data analysis}

$\mathrm{P}-\mathrm{V}$ curves for respiratory system and subcomponents were constructed and regression lines for three to four consecutive points were determined. At $\geqslant 20 \%$ increase in regression line slope, the point of intersection of the linear tracts, identifying the zones of initial (starting) low compliance and of inflation (maximal) compliance was identified as LIP [14, 17]. Accordingly, at $\geqslant 20 \%$ decrease in regression line slope, the point of intersection of the linear tracts, identifying the zones of maximal compliance and of final low compliance was identified as UIP $[14,17]$. Starting compliance was determined as the inflation volume at LIP divided by LIP pressure. Maximal compliance was determined as the inflation volume difference between UIP and LIP divided by the corresponding pressure difference. Final compliance was determined as the difference between 1,200 mL (first 11 patients) or $1,500 \mathrm{~mL}$ (last five patients) and UIP inflation volume divided by the corresponding pressure difference. Each diagram was encoded as recently described [17] and analysed by two independent observers. Following diagram evaluations, codes were broken and means of observer-determined variable values were analysed.

\section{Respiratory mechanics and lung volumes}

Respiratory mechanics were assessed with rapid end-expiratory/end-inspiratory airway occlusion. Within 65-70 min after study posture assumption, four test breaths (with baseline ventilatory settings maintained unchanged) were administered. Determined/computed variables for the respiratory system and subcomponents included: 1) static intrinsic PEEP (PEEPi); and 2) maximal, interrupter and additional resistances, and dynamic and static compliances (Appendix II). Dynamic PEEPi,rs was defined as the increment in inspiratory tracheal pressure needed for expiratory flow termination and initiation of lung inflation [2, 18]. Dynamic PEEPi was determined at baseline ventilation breaths that preceded test breaths [2]. For each posture, only means of variable value sets were analysed. Additional determined variables were expiratory airway resistance at EELV, time of FRC change ( $\triangle$ FRC) expiration, and mean end-expiratory flow (Appendix II) [2]. At 85-90 min following study posture assumption, baseline ventilation $\triangle F R C$ was measured by allowing exhalation to FRC $[1,2]$. Immediately thereafter, FRC was determined by helium-dilution technique (Appendix II) [2]. Baseline ventilation was then resumed for $15 \mathrm{~min}$, the endotracheal tube was clamped during an end-expiratory occlusion and EELV was determined by helium-dilution technique. In each posture, the protocol was concluded after another $15 \mathrm{~min}$ of baseline ventilation.

\section{Opening volume}

The lung volume corresponding to the LIP pressure of the respiratory system $\mathrm{P}-\mathrm{V}$ curve was defined as the opening volume [5]; this was computed as the sum of FRC and the LIP inflation volume.

\section{Statistical analysis}

Data sets obtained in different body postures were compared with univariate repeated measures analysis of variance, followed by Scheffé test as appropriate. Multiple linear regression analysis was performed by the stepwise method. The variable entry and removal criteria were $p<0.05$ and $p>0.1$, respectively. Significance was accepted at $p<0.05$. Data are presented as mean \pm SEM. 


\begin{tabular}{|c|c|c|c|c|c|c|c|c|c|}
\hline Pre-prone SREC & $93 \pm 2$ & $79 \pm 2$ & $9 \pm 1$ & $24 \pm 1$ & $11 \pm 1$ & $3.5 \pm 0.1$ & $146 \pm 2$ & $1637 \pm 66$ & $307 \pm 17$ \\
\hline Prone & $90 \pm 2$ & $82 \pm 2$ & $9 \pm 1$ & $23 \pm 1$ & $10 \pm 1$ & $3.5 \pm 0.1$ & $149 \pm 4$ & $1698 \pm 80$ & $292 \pm 18$ \\
\hline Post-prone SREC & $90 \pm 2$ & $80 \pm 2$ & $9 \pm 1$ & $25 \pm 1$ & $11 \pm 1$ & $3.3 \pm 0.1$ & $146 \pm 5$ & $1786 \pm 82$ & $334 \pm 21$ \\
\hline
\end{tabular}

Data are presented as mean \pm SE. $f$ C: cardiac frequency; MAP: mean arterial pressure; CVP: central venous pressure; $P$ pa: mean pulmonary artery pressure; $P$ pw: pulmonary artery wedge pressure; $\mathrm{Cl}$ : cardiac index; $\mathrm{V}^{\prime} \mathrm{O}_{2}$ : oxygen consumption; SVRI: systemic vascular resistance index; PVRI: pulmonary vascular resistance index; SREC: semirecumbent. $1 \mathrm{mmHg}=0.133 \mathrm{kPa}$.

\section{RESULTS}

Full data were obtained from all patients and no protocolrelated complications [1] occurred. Gastric pressure was unaffected by body posture (data not shown).

\section{Haemodynamics and gas exchange}

Haemodynamic variables were unaffected by posture change. Prone position versus pre-prone SREC resulted in improved oxygenation and lower $\mathrm{Pa}_{1} \mathrm{CO}_{2}$ (tables 2 and 3).

\section{PV curves}

Figure 1 displays average $\mathrm{P}-\mathrm{V}$ curves. Pronation resulted in shifting of the lung $\mathrm{P}-\mathrm{V}$ curve to the left. LIPs were identified on the respiratory system, and lung and chest wall $\mathrm{P}-\mathrm{V}$ curves in all patients and postures.

Regarding respiratory system $\mathrm{P}-\mathrm{V}$ curves, there were no posture-related differences in determined $\mathrm{P}-\mathrm{V}$ curve variables. In the last five patients, UIPs were identified at inflation volumes of $0.87-1.18 \mathrm{~L}$ (table 4 ). In the first 11 patients, UIPs were not identified, because the determined decreases in the regression line slopes used to identify UIP were close to (i.e. $17-19 \%$ ) but not greater than the pre-determined value of $20 \%$ (see Methods section). Based on results from the second patient subset, the current authors speculate that the number of the $\mathrm{P}-\mathrm{V}$ data points corresponding to high inflation volumes was insufficient to actually identify existing UIPs.

Regarding lung $\mathrm{P}-\mathrm{V}$ curves, the LIP corresponded to lower pressure and similar volume in prone versus pre-prone/postprone SREC. Maximal lung compliance was greater in prone versus pre-prone SREC (table 4). In pre-prone and post-prone SREC, UIPs were identified in 10 out of the first 11 patients. Pressures/volumes were $17.7 \pm 0.3 \mathrm{cmH}_{2} \mathrm{O} / 0.99 \pm 0.01 \mathrm{~L}$ and $15.4 \pm 1.0 \mathrm{cmH}_{2} \mathrm{O} / 0.85 \pm 0.02 \mathrm{~L}$ in pre- and post-prone SREC, respectively. UIP identification corresponded to decreases in regression line slopes by $20-22 \%$. In the prone position, UIPs were not identified in the first 11 patients, probably because of insufficient $\mathrm{P}-\mathrm{V}$ data points corresponding to high (i.e. $>1.0 \mathrm{~L}$ ) inflation volumes. In the last five patients UIPs were identified in all postures, with the corresponding volumes being highest in the prone position(table 4).

Regarding chest wall $\mathrm{P}-\mathrm{V}$ curves, starting chest wall compliance was lower in prone versus post-prone SREC. Maximal chest wall compliance was lower in prone versus pre-prone/ post-prone SREC (table 4).

\section{Respiratory mechanics and lung volumes}

Pronation versus SREC improved lung mechanics and reduced PEEPi, $\triangle F R C$, FRC, opening volume and EELV (table 5). Notably, opening volume was always exceeded by EELV (fig. 2).

\section{Regression analyses}

Figure 3 displays the main results of bivariate regression analyses. Results of multiple, stepwise linear regression analyses are reported as follows.

Changes in PEEPi,rs from pre-prone SREC to prone were the sole independent predictor of concomitant changes in lung LIP pressure (dependent variable: LIP pressure changes;

\section{TABLE 3 Gas exchange}

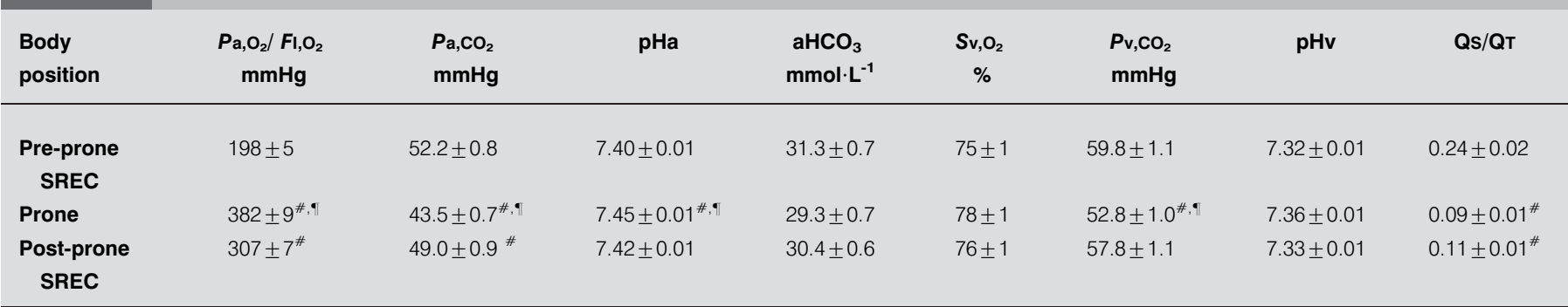

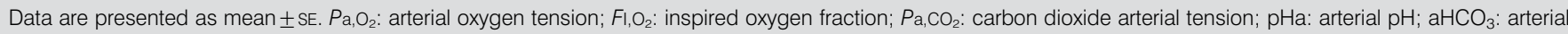

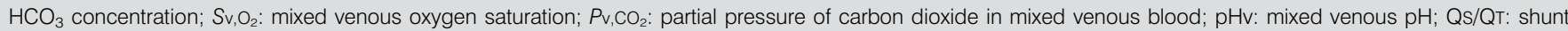
fraction; SREC: semirecumbent. ${ }^{*}: \mathrm{p}<0.05$ versus pre-prone SREC; ${ }^{\bullet}: \mathrm{p}<0.05$ versus post-prone SREC. $1 \mathrm{mmHg}=0.133 \mathrm{kPa}$. 

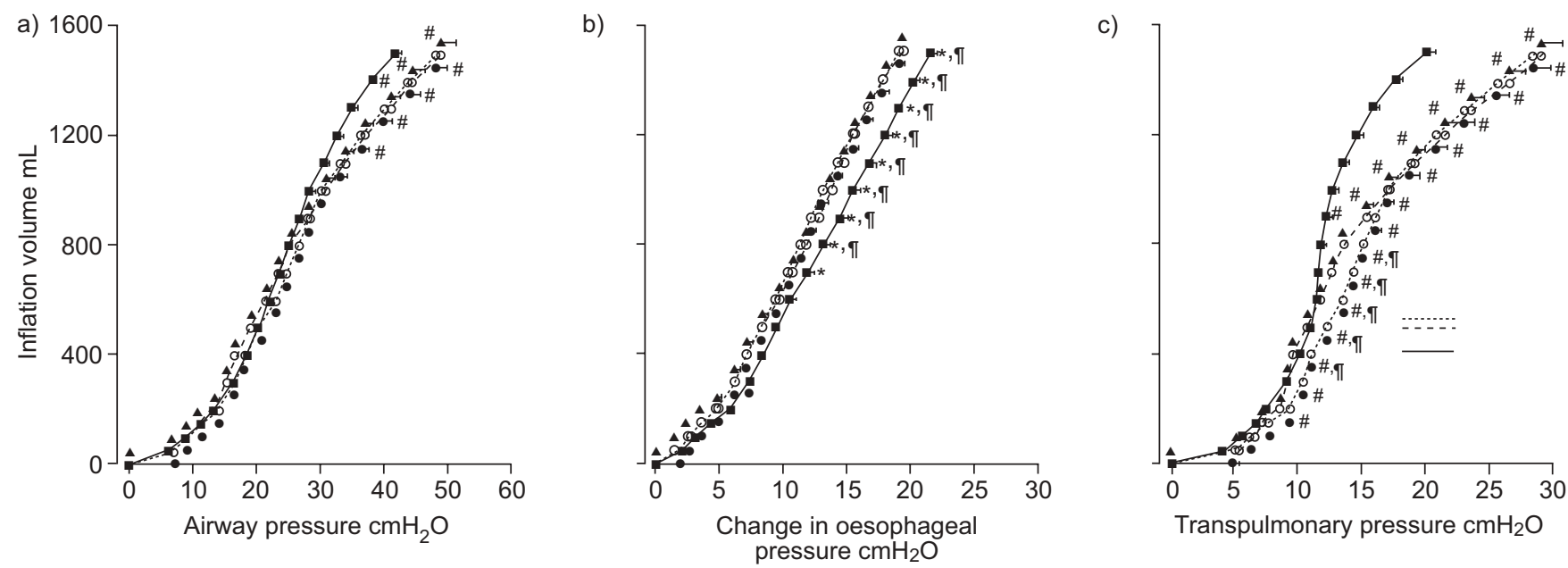

FIGURE 1. Average pressure-volume curves of a) the respiratory system, b) chest wall, and c) lung. Data corresponding to an inflation volume of up to $1,200 \mathrm{~mL}$ are from 16 patients, whereas data corresponding to higher inflation volumes are from the last five patients enrolled. - - mean end-expiratory lung volume (EELV) in prone (406.7); - - -: EELV in post-prone semirecumbent (SREC; 495.6); …....: EELV in pre-prone SREC (524.4). $\mathbf{~}$ : prone; $\bullet$ : pre-prone SREC; $\mathbf{\Lambda}$ : post-prone SREC. *: p<0.05 significantly different pressure value versus pre-prone SREC positions; ${ }^{*}: p<0.05$ significantly different pressure value versus prone; ${ }^{n}: p<0.05$ significantly different pressure value versus post-prone SREC.

independent variables: changes in respiratory mechanics variables and lung volumes).

Changes in additional lung resistance from pre-prone SREC to prone were the sole independent predictors of concomitant changes in $\mathrm{Pa}, \mathrm{CO}_{2}$ (dependent variable: changes in $\mathrm{Pa}, \mathrm{CO}_{2}$; independent variables: changes in respiratory mechanics, $\mathrm{P}-\mathrm{V}$ curve-derived variables, and lung volumes). Changes in additional lung resistance from pre-prone SREC to prone were also the only independent predictors of concomitant changes in expiratory airway resistance at EELV and EELV (dependent variables: respective changes in expiratory resistance and EELV; independent variables: changes in respiratory mechanics; P-V curve-derived variables, and lung volumes).

\section{DISCUSSION}

The main results of the present study were that during early controlled ventilation of patients with severe chronic bronchitis and high PEEPi,rs: 1) prone position reduces LIP pressure and increases UIP volume of the lung P-V curve; 2) EELV exceeds opening volume; 3) prone position decreases $\mathrm{Pa}_{\mathrm{a}} \mathrm{CO}_{2}$; and 4) postural decreases in PEEPi,rs and additional lung resistance predict postural decreases in lung LIP pressure and $\mathrm{Pa}_{1} \mathrm{CO}_{2}$, respectively. Other results were mainly confirmative of previously published and interpreted findings [1, 2].

\section{Prone position and P-V curve morphology}

Pronation contributes to re-aeration of previously closed lung units by relieving regional lung compression by the heart and/or

TABLE 4 Results on pressure-volume curve derived variables

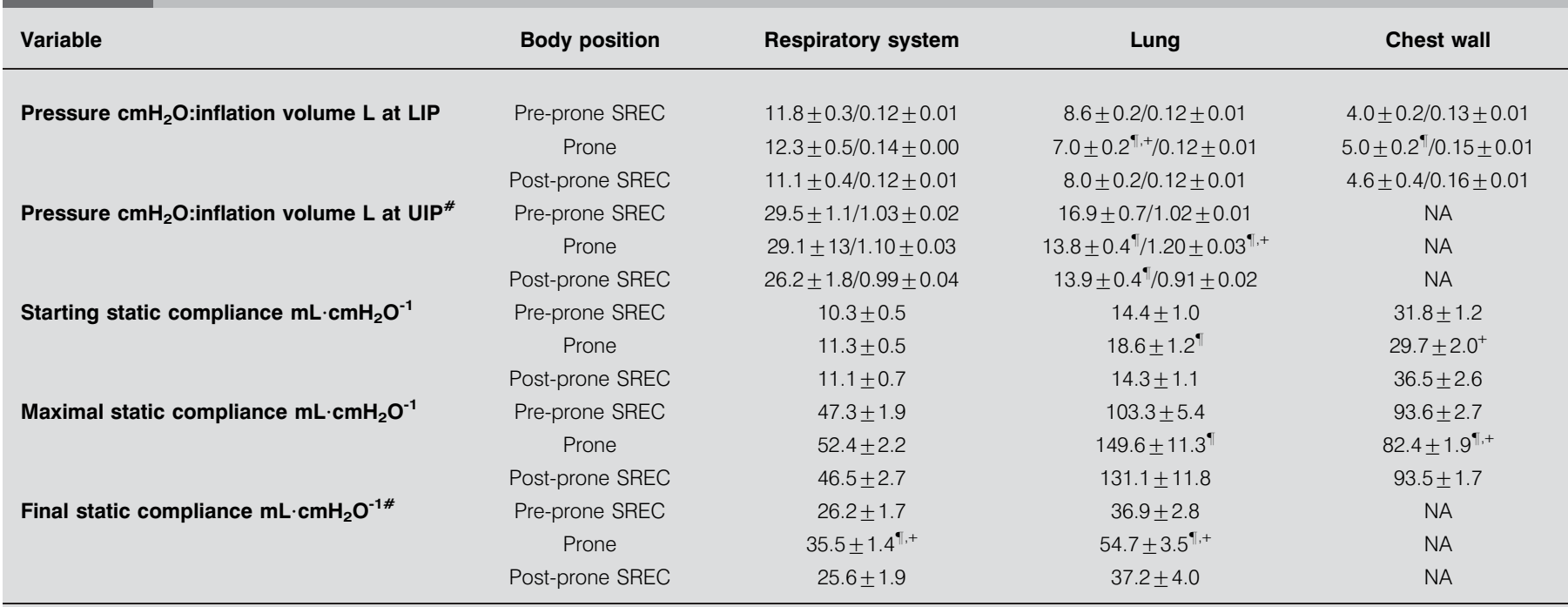

Data are presented as mean \pm SE. LIP: lower inflection point; UIP: upper inflection point; SREC: semirecumbent; NA: not applicable. ${ }^{\#}$ : data are from the last five consecutive patients enrolled (see Material and methods section); ${ }^{\uparrow}: p<0.05$ versus pre-prone SREC; ${ }^{+}: p<0.05$ versus post-prone SREC. 


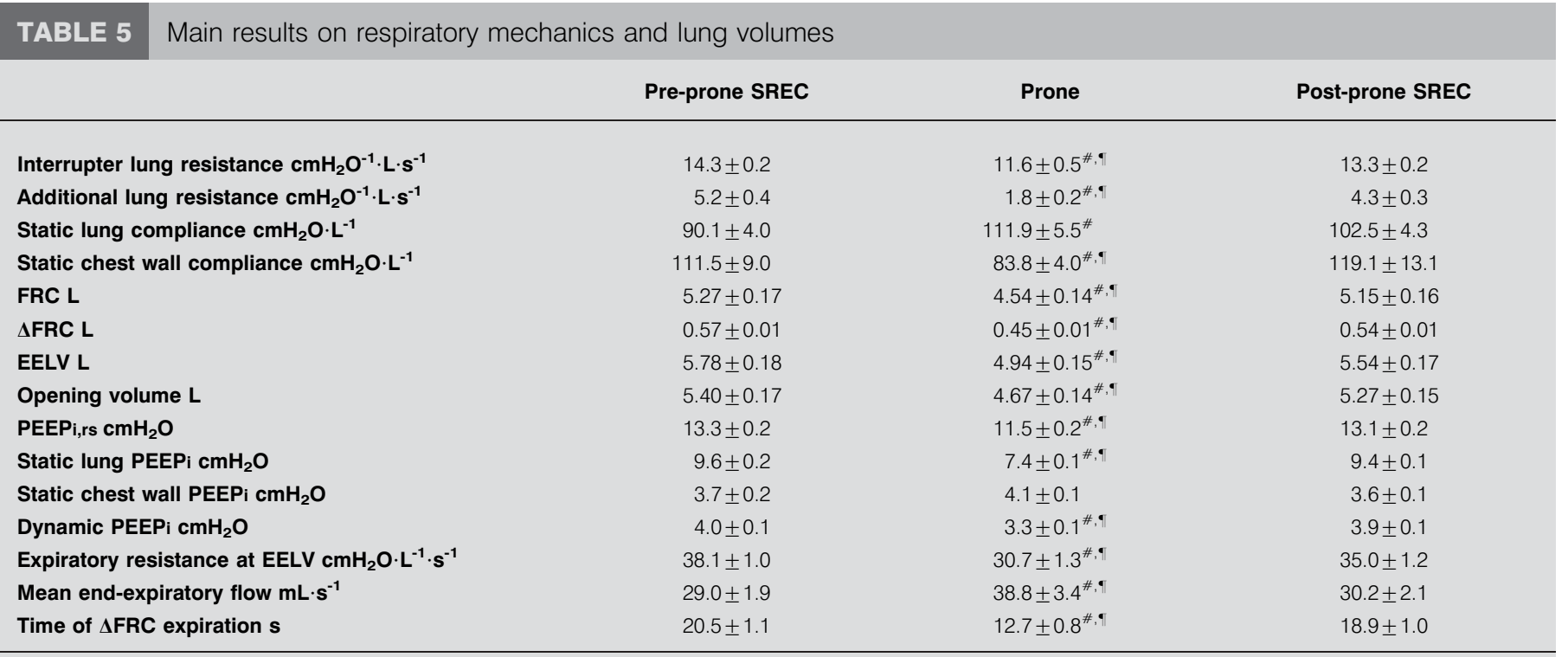

Data are presented as mean \pm SE. SREC: semirecumbent; FRC: functional residual capacity; $\triangle F R C$ : change in functional residual capacity; EELV: end-expiratory lung volume; PEEPi,rs: static respiratory system intrinsic positive end-expiratory pressure; PEEPi: intrinsic positive end-expiratory pressure; EELV: end-expiratory lung volume. ${ }^{\#}$ : $p<0.05$ significantly different versus pre-prone SREC; ${ }^{\bullet}: p<0.05$ significantly different versus post-prone SREC.

abdominal contents $[1,2,19,20]$. This is consistent with prior $[1,2]$ and current results on lung compliance/ additional resistance. In the prone position, the stiffer, vertebral chest wall component becomes nondependent, resulting in augmented aeration of dependent lung units [21] and, probably, attenuated hyperinflation of nondependent lung units. This concept is supported by the current results from lung UIP volume measurements.

In contrast to other studies [5, 15, 22], the present authors could identify UIPs on respiratory system and lung P-V curves, because higher volumes were administered and additional $\mathrm{P}-\mathrm{V}$ data points obtained (fig. 1; table 4). In SREC, the lung UIP presence at 0.2-0.6 L above EELV (fig. 1c; table 5) suggests that if total PEEP and EELV are increased by applying external

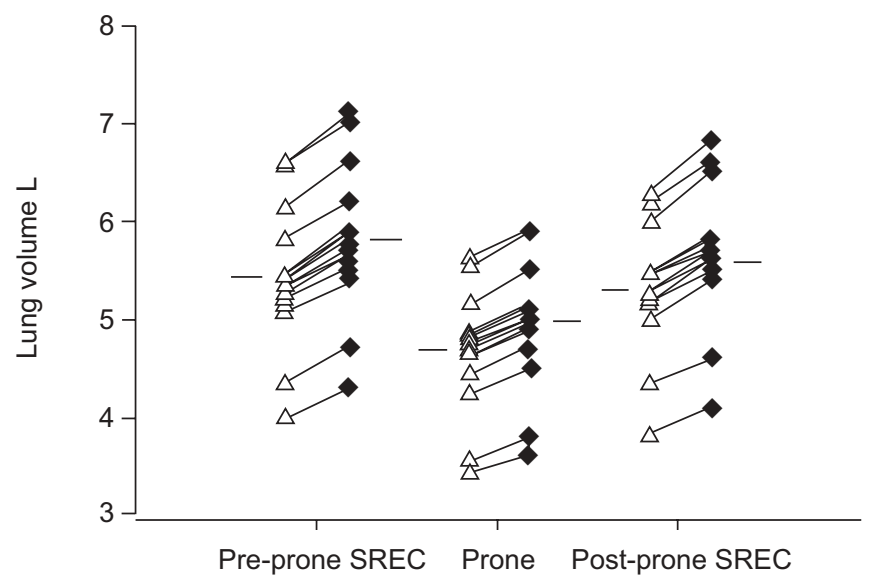

FIGURE 2. Individual values of end-expiratory lung volume ( $)$ and opening volume $(\triangle)$. Horizontal lines represent mean values. Lines connect value pairs from each patient. SREC: semirecumbent.
PEEP [8], the risk of alveolar overdistension/barotrauma during tidal lung inflation (table 1) will probably increase as well. In contrast, in the prone position, the lung UIP level exceeded EELV by $0.7-0.8 \mathrm{~L}$ (last five patients), indicating a reduced risk of over-distension during tidal lung inflation (fig. 1c; table 1).

Results from lung LIP pressure measurements indicated that small airway reopening during lung inflation from the FRC level in the prone position was facilitated. Moreover, the reductions in dynamic hyperinflation, expiratory resistance and increases in mean end-expiratory flow indicated attenuated expiratory airway closure or narrowing in the prone position [2]. This explains the pronation-facilitated, inspiratory peripheral airway re-opening, and is consistent with the observed association between postural decreases in PEEPi,rs and lung LIP pressure (fig. 3a).

EELV/opening volume relationships determined in the current study were similar to three out of 10 COPD patients studied previously by GUÉRIN et al. [8] and all COPD patients studied previously by BROSEGHINI et al. [4]. In the study by GUÉRIN et al. [8], patients exhibited moderate PEEPi,rs $\left(7.1 \pm 1.3 \mathrm{cmH}_{2} \mathrm{O}\right)$ and were enrolled after $3.0 \pm 0.8$ days of mechanical ventilation. However, as in the present study, BROSEGHINI et al. [4] studied patients with high PEEPi,rs $\left(13.5 \pm 2.4 \mathrm{cmH}_{2} \mathrm{O}\right)$ within $36 \mathrm{~h}$ of controlled ventilation onset.

Prone position and $\mathrm{Pa}, \mathrm{CO}_{2}$

Expiratory airway stabilisation was attributed to a postural homogenisation of the alveolar septal tension that is transmitted to airway walls [2]. Current additional lung resistance results imply reduction in lung time constant inequality and more homogenous distribution of ventilation $[1,2,15]$ and alveolar septal tension [2]. Also, regression analyses results indicate that pronation primarily causes more homogenous 

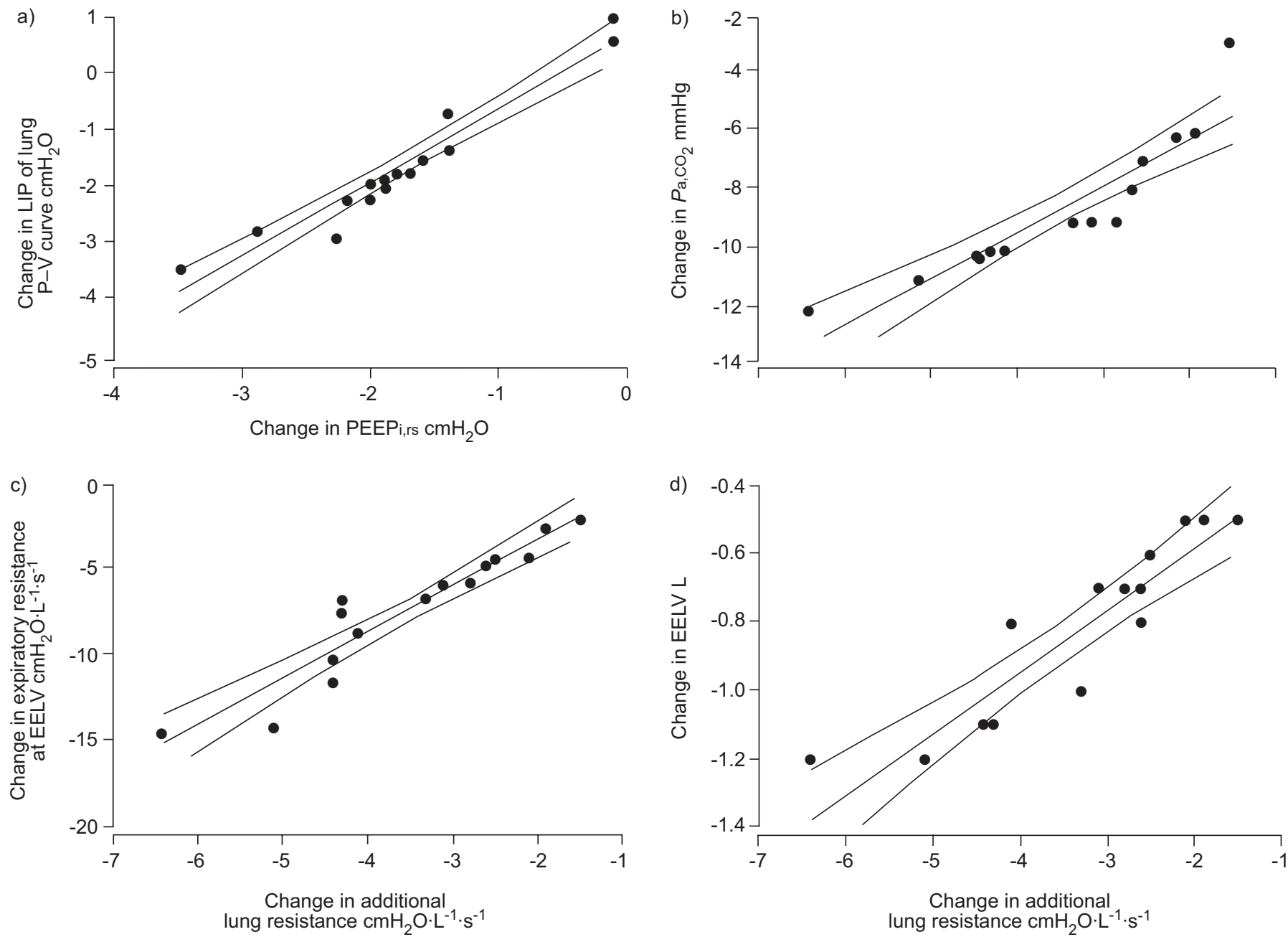

FIGURE 3. Scatter plots of individual, pre-prone semirecumbent to prone changes in a) static respiratory system intrinsic positive end-expiratory pressure (PEEPi,rs) and pressure at the lower inflection point (LIP) of the lung pressure-volume ( $\mathrm{P}-\mathrm{V})$ curve; b) additional lung resistance and carbon dioxide arterial tension $\left(\mathrm{Pa}_{\mathrm{a}} \mathrm{CO}_{2}\right)$; $\left.\mathrm{c}\right)$ additional lung resistance and expiratory airway resistance at end-expiratory lung volume (EELV); and d) additional lung resistance and EELV. The curves at either side of the regression lines represent $95 \%$ confidence limits. a) $\left.\left.y=0.68+1.31 \times x, r^{2}=0.93, p<0.001 ; b\right) y=3.27+1.55 \times x, r^{2}=0.83, p<0.001 ; c\right) \quad y=1.96+2.69 \times x, r^{2}=0.89, p<0.001$; d) $y=-0.22+0.18 \times x, r^{2}=0.84, p<0.001$

distribution of ventilation and alveolar septal tension, thus leading to reduced $\mathrm{Pa}_{\mathrm{a}} \mathrm{CO}_{2}$, expiratory resistance and EELV (fig. $3 b-d)$.

The current $\mathrm{Pa}_{\mathrm{a}} \mathrm{CO}_{2}$ results differ from those of three recent studies [1-3]. In contrast to the first two [1, 2], severely hyperinflated patients ( $\mathrm{PEEPi}, \mathrm{rs} 13.4 \pm 0.2 \mathrm{cmH}_{2} \mathrm{O}$ ) were enrolled in the current study as early as possible (mechanical ventilation duration $<36 \mathrm{~h}$ ) during the course of disease exacerbation. Notably, the pronation-induced decrease in additional lung resistance $(\sim 65 \%)$ was maximised relative to these studies $[1,2]$ and, thus, explains the significant $\mathrm{Pa}, \mathrm{CO}_{2}$ reduction (fig. $3 b$ ).

In the third study [3], the effects of three consecutive pronation sessions on gas exchange and secretion drainage in 11 COPD patients were evaluated. Pronation improved oxygenation but not $\mathrm{Pa}, \mathrm{CO}_{2} . P \mathrm{a}, \mathrm{CO}_{2}$ exhibited a nonsignificant reduction and secretion drainage was improved during the first pronation session. Group homogeneity was not controlled according to the cause of COPD exacerbation (acute bronchitis or pneumonia); asthma, morbid obesity or prior tuberculosis history [20]; and possibly, disease severity. Patients were enrolled after 18$196 \mathrm{~h}$ of controlled ventilation, and external PEEP was $7.0 \pm 0.9 \mathrm{cmH}_{2} \mathrm{O}$ (as opposed to $0 \mathrm{cmH}_{2} \mathrm{O}$ in the present study). Finally, pronation technique was not aimed at minimising abdominal movement restriction [1, 2, 21]. Indeed, a support was not placed under the pelvis. This could have prevented the pronation-induced relief of lung compression by the abdominal contents $[3,19,20]$.

\section{Clinical implications}

The results of the current physiological study suggest that pronation effects with respect to hyperinflation and $\mathrm{Pa}_{2} \mathrm{CO}_{2}$ are maximised during early controlled ventilation of chronic bronchitis patients with high PEEPi,rs. Pronation effects on $P a, C_{2}$ suggest that a reduction in tidal volume and/or respiratory rate and minute ventilation may be feasible. The former manoeuvre may minimise alveolar overdistension 
during tidal breathing, whereas the latter may result in increased expiratory time and further attenuation of hyperinflation.

In the present study, EELV always exceeded opening volume. To the extent that cyclic closure/reopening of small airways has an impact in COPD [8], this finding implies that external PEEP is not recommendable to prevent low-volume barotrauma [8]. However, this may not be applicable for patients with less severe hyperinflation (e.g. PEEPi,rs $\left.<10 \mathrm{cmH}_{2} \mathrm{O}\right)$ [23]. Also, during partial ventilatory support, external PEEP is actually recommendable when flow limitation is present because it facilitates ventilator triggering and unloading of inspiratory muscles [24, 25].

\section{Conclusions}

Prone positioning of severely hyperinflated chronic obstructive pulmonary disease patients reduces lung lower inflection point pressure and increases upper inflection point volume. Furthermore, pronation-induced improvements in ventilation homogeneity (demonstrated by decreased additional lung resistance) and carbon dioxide arterial tension are maximised, thus suggesting that prone positioning can be a useful and/or preferable ventilatory strategy during early controlled ventilation.

\section{APPENDIX I - FORMULAE USED TO DERIVE HAEMODYNAMIC AND GAS EXCHANGE VARIABLES [26, 27]}

1. Cardiac index $=\mathrm{CO} / \mathrm{BSA}[28]$

2. Systemic vascular resistance index $=(\mathrm{MAP}-\mathrm{CVP}) \cdot 80 / \mathrm{CI}$

3. Pulmonary vascular resistance index $=(\mathrm{MPAP}-\mathrm{Ppw}) \cdot 80 / \mathrm{CI}$

4. $\mathrm{O}_{2}$ consumption per $\mathrm{m}^{2} \mathrm{BSA}=\mathrm{CI} \cdot 1.36 \cdot \mathrm{Hgb} \cdot\left(\mathrm{Sa}_{\mathrm{a}} \mathrm{O}_{2}-\mathrm{S}_{\mathrm{v}}, \mathrm{O}_{2}\right)$

5. Respiratory quotient $=($ FEY of carbohydrate intake $) \cdot 1.0+($ FEY of protein intake) $\cdot 0.8+(\mathrm{FEY}$ of lipid intake $) \cdot 0.7$ [29]

6. Alveolar $P_{\mathrm{O}_{2}}=P \mathrm{i}, \mathrm{O}_{2}-P A, \mathrm{CO}_{2} \cdot\left[F \mathrm{I}, \mathrm{O}_{2}-\left(1-F \mathrm{I}, \mathrm{O}_{2}\right) \cdot \mathrm{R}^{-1}\right] ; P \mathrm{I}, \mathrm{O}_{2}=F \mathrm{I}, \mathrm{O}_{2}$ (PB-47); $P \mathrm{~A}, \mathrm{CO}_{2} \sim \mathrm{Pa}_{1} \mathrm{CO}_{2}$

7. $\mathrm{O}_{2}$ content of blood $=\mathrm{Hgb} \cdot 1.36 \cdot S, \mathrm{O}_{2} / 10+0.003 \cdot \mathrm{PO}_{2}$

8. Shunt fraction $=\left(\mathrm{C}_{\mathrm{c}, \mathrm{O}_{2}}-\mathrm{Ca}_{\mathrm{a}} \mathrm{O}_{2}\right) /\left(\mathrm{C}_{\mathrm{c}, \mathrm{O}_{2}}-\mathrm{C}_{\mathrm{v}}, \mathrm{O}_{2}\right)$

$\mathrm{CO}$ : cardiac output $\left(\mathrm{L} \cdot \mathrm{min}^{-1}\right)$; BSA: body surface area $\left(\mathrm{m}^{2}\right)$; MAP: mean arterial pressure (mmHg); CVP: central venous pressure $(\mathrm{mmHg})$; 80: transformation factor of Wood units $\left(\mathrm{mmHg} \cdot \mathrm{L}^{-1} \cdot \mathrm{min}\right)$ to standard metric units (dynes $\left.\cdot \mathrm{s} \cdot \mathrm{cm}^{-5}\right)$; CI: cardiac index $\left(\mathrm{L} \cdot \mathrm{min}^{-1} \cdot \mathrm{m}^{-2}\right)$; MPAP: mean pulmonary artery pressure (mmHg); Ppw: pulmonary artery wedge pressure $(\mathrm{mmHg}) ; 1.36: \mathrm{O}_{2}$ combining power of $1 \mathrm{~g}$ of haemoglobin $(\mathrm{mL})$; Hgb: haemoglobin concentration $\left(\mathrm{g} \cdot \mathrm{L}^{-1}\right) ; \mathrm{Sa}_{2} \mathrm{O}_{2}$ : arterial oxygen saturation; $\mathrm{S}_{\mathrm{v}, \mathrm{O}_{2}}$ : mixed venous oxygen saturation; FEY: fractional energy yield relative to total of prescribed nutritional support; $\mathrm{PO}_{2}$ : oxygen partial pressure $(\mathrm{mmHg})$; $\mathrm{PI}_{\mathrm{I}} \mathrm{O}_{2}$ : inspired oxygen partial pressure $(\mathrm{mmHg}) ; \mathrm{PA}_{1} \mathrm{CO}_{2}$ : alveolar carbon dioxide partial pressure $(\mathrm{mmHg}) ; \mathrm{Pa}_{1} \mathrm{CO}_{2}$ : carbon dioxide arterial tension: $\mathrm{FI}_{2} \mathrm{O}_{2}$ : inspired oxygen fraction; R: respiratory quotient; $P_{\mathrm{B}}$ : barometric pressure $(\mathrm{mmHg}) ; 47$ : water saturated vapour pressure at $37^{\circ} \mathrm{C}(\mathrm{mmHg}) ; 0.003$ : oxygen solubility coefficient at $37^{\circ} \mathrm{C}\left(\mathrm{mL} \cdot \mathrm{dL}^{-1} \cdot \mathrm{mmHg}^{-1}\right) ; S, \mathrm{O}_{2}$ : oxygen saturation; $\mathrm{C}_{\mathrm{c}}, \mathrm{O}_{2} / \mathrm{Ca}_{2} \mathrm{O}_{2} / \mathrm{C}_{\mathrm{v}}, \mathrm{O}_{2}$ : oxygen content in endcapillary/arterial/mixed-venous blood, respectively.

\section{APPENDIX II - INSPIRATORY AND EXPIRATORY MECHANICAL VARIABLES AND FUNCTIONAL RESIDUAL CAPACITY}

A) For the respiratory system, chest wall and lung the following inspiratory mechanical variables were determined: 1) maximal, interrupter and "additional" resistances, defined as respective differences between maximal pressure $(P \max )$ and plateau pressure $\left(P_{2}\right), P \max$ and pressure immediately after initiation of end-inspiratory airway occlusion $\left(P_{1}\right)$, and $P_{1}$ and $P_{2}$, divided by the preceding inspiratory flow; and 2) dynamic and static compliances, defined as ventilator-administered inflation volume divided by the respective differences between $P_{1}$ and static intrinsic positive end-expiratory pressure (PEEPi), and $P_{2}$ and static PEEPi. Interrupter and additional lung resistance reflect the inspiratory, "ohmic" airway resistance and "additional" resistance due to lung tissue stress relaxation tension and time constant inequality, respectively.

B) Expiratory airway resistance at end-expiratory lung volume (EELV) was computed as dynamic PEEPi divided by expiratory flow at EELV [2]. Time of change in functional residual capacity $(\triangle F R C)$ expiration was defined as the time needed for the lungs to reduce their volume from EELV to FRC during passive exhalation [2]. Mean end-expiratory flow was determined as average expiratory flow during the period of $\triangle F R C$ expiration [2].

C) FRC and EELV were determined with a modified closedcircuit helium dilution technique, which comprises administration of 20 deep manual breaths at a rate of 4 cycles $\cdot \mathrm{min}^{-1}$ [2]. An anaesthesia bag filled with $2.0 \mathrm{~L}$ of $13 \%$ helium in oxygen and a helium analyser (PK Morgan Ltd, Rainham, UK) were used.

\section{REFERENCES}

1 Mentzelopoulos SD, Zakynthinos SG, Roussos C, Tzoufi MJ, Michalopoulos AS. Prone position improves lung mechanical behavior and enhances gas exchange efficiency in mechanically ventilated chronic obstructive pulmonary disease patients. Anesth Analg 2003; 96: 1756-1767.

2 Mentzelopoulos SD, Roussos C, Zakynthinos SG. Prone position improves expiratory airway mechanics in severe chronic bronchitis. Eur Respir J 2005; 25: 259-268.

3 Reignier J, Lejeune O, Renard B, et al. Short-term effects of prone position in chronic obstructive pulmonary disease patients with severe acute and hypercapnic respiratory failure. Intensive Care Med 2005; 31: 1128-1131.

4 Broseghini C, Brandolese R, Poggi R, et al. Respiratory mechanics during the first day of mechanical ventilation in patients with pulmonary edema and chronic airway obstruction. Am Rev Respir Dis 1988; 138: 355-361.

5 Marthan R, Castaing Y, Manier G, Guenard H. Gas exchange alterations in patients with chronic obstructive lung disease. Chest 1985; 87: 470-475.

6 Shim C, Chun KJ, Williams MH Jr, Blaufox MD. Positional effects on distribution of ventilation in chronic obstructive pulmonary disease. Ann Intern Med 1986; 105: 346-350. 
7 Torres A, Reyes A, Roca J, Wagner PD, Rodriguez-Roisin R. Ventilation-perfusion mismatching in chronic obstructive pulmonary disease during ventilator weaning. Am Rev Respir Dis 1989; 140: 1246-1250.

8 Guérin C, Lemasson S, de Varax R, Milic-Emili J, Fournier G. Small airway closure and positive endexpiratory pressure in mechanically ventilated patients with chronic obstructive pulmonary disease. Am J Respir Crit Care Med 1997; 155: 1949-1956.

9 American Thoracic Society. Standards for the diagnosis and care of patients with chronic obstructive pulmonary disease. Am J Respir Crit Care Med 1995; 152: Suppl., 77S$121 S$.

10 American Thoracic Society, Lung function testing: selection of reference values and interpretive strategies. Am Rev Respir Dis 1991; 144: 1208-1218.

11 Mannino DM. COPD. Epidemiology, prevalence, morbidity and mortality, and disease heterogeneity. Chest 2002; 121: Suppl. 5, 121S-126S.

12 Hankinson JL, Odencrantz JR, Fedan JB. Spirometric reference values from a sample of the general U.S. population. Am J Respir Crit Care Med 1999; 159: 178-187.

13 Baydur A, Behrakis PK, Zin WA, Jaeger M, Milic-Emili J. A simple method for assessing the validity of the esophageal balloon technique. Am Rev Respir Dis 1982; 126: 788-791.

14 Ranieri VM, Brienza N, Santostasi S, et al. Impairment of lung and chest wall mechanics in patients with acute respiratory distress syndrome. Role of abdominal distention. Am J Respir Crit Care Med 1997; 156: 1082-1091.

15 Coussa ML, Guérin C, Eissa NT, et al. Partitioning of work of breathing in mechanically ventilated COPD patients. $J$ Appl Physiol 1993; 75: 1711-1719.

16 Harris RS, Hess DR, Venegas JG. An objective analysis of the pressure-volume curve in the acute respiratory distress syndrome. Am J Respir Crit Care Med 2000; 161: 432-439.

17 Mentzelopoulos SD, Roussos C, Zakynthinos SG. Static pressure volume curves and body posture in acute respiratory failure. Intensive Care Med 2005; 31: 1683-1692.

18 Maltais F, Reissmann H, Navalesi P, et al. Comparison of static and dynamic measurements of intrinsic PEEP in mechanically ventilated patients. Am J Respir Crit Care Med 1994; 150: 1318-1324.

19 Albert RK, Hubmayr RD. The prone position eliminates compression of the lungs by the heart. Am J Respir Crit Care Med 2000; 161: 1660-1665.

20 Rouby JJ, Puybasset L, Niezkowska A, Lu Q. Acute respiratory distress syndrome: lessons from computed tomography of the whole lung. Crit Care Med 2003; 31: Suppl. 4, S285-S295.

21 Pelosi P, Tubiolo D, Mascheroni D, et al. Effects of the prone position on respiratory mechanics and gas exchange during acute lung injury. Am J Respir Crit Care Med 1998; 157: 387-393.

22 Ranieri VM, Giuliani R, Mascia L, et al. Lung and chest wall contribution to the elastic properties of the respiratory system in patients with chronic obstructive pulmonary disease. Eur Respir J 1996; 9: 1232-1239.

23 Tzoufi MJ, Mentzelopoulos SD, Roussos C, Armaganidis A. Effects of nebulized salbutamol, external positive endexpiratory pressure, and their combination on respiratory mechanics, hemodynamics, and gas exchange in mechanically ventilated chronic obstructive pulmonary disease patients. Anesth Analg 2005; 101: 843-850.

24 Marini JJ. Should PEEP be used in airflow obstruction? Am Rev Respir Dis 1989; 140: 1-3.

25 Rossi A, Appendini L, Ranieri VM. PEEP and CPAP in severe airflow obstruction. In: Marini JJ, Slutsky AS, eds. Physiological Basis of Ventilatory Support. New York, Marcel Dekker, 1998; pp. 847-873.

26 Mark JB, Slaughter TF, Reves JG. Cardiovascular monitoring. In: Miller RD, ed. Anesthesia. 5th Ed. New York, Churchill Livingstone, 2000; pp. 1117-1230.

27 Moon ME, Camporesi EM. Respiratory monitoring. In: Miller RD, ed. Anesthesia. 5th Edn. New York, Churchill Livingstone, 2000; pp. 1255-1296.

28 Mosteller RD. Simplified calculation of body-surface area. N Engl J Med 1987; 317: 1098.

29 Marino PL. Nutrient and energy requirements. In: Marino PL, ed. The ICU book. 2nd Edn. Baltimore, Williams \& Wilkins, 1997; pp. 721-736. 